\title{
Early aEEG can predict neurodevelopmental outcomes at 12 to 18 month of age in VLBWI with necrotizing enterocolitis: a cohort study
}

Si Chen', Xiuman Xiao', Su Lin', Jianghu Zhu', Lidan Liang², Minli Zhu', Zuqin Yang', Shangqin Chen', Zhenlang Lin ${ }^{1 *}$ and Yanli Liu ${ }^{* *}$

\begin{abstract}
Background: Studies have shown that neurological damage is common in necrotizing enterocolitis (NEC) survivors. The purpose of the study was to investigate the predictive value of amplitude-integrated electroencephalogram (aEEG) for neurodevelopmental outcomes in preterm infants with NEC.
\end{abstract}

Methods: Infants with NEC were selected, and the control group was selected based on 1:1-2 pairing by gestational age. We performed single-channel (P3-P4) aEEG in the two groups. The Burdjalov scores were compared between the two groups. Cranial magnetic resonance imaging (MRI) was performed several months after birth. The neurological outcomes at 12 to 18 months of age were compared with the Gesell Developmental Schedules (GDS). The predictive value of aEEG scores for neurodevelopmental delay was calculated.

Results: There was good consistency between the two groups regarding general conditions. In the $1 \mathrm{st}$ aEEG examination, the patients in NEC group had lower Co $(1.0(0.0,2.0)$ vs. $2.0(2.0,2.0), P=0.001)$, Cy $(1.0(0.0,2.0)$ vs. 3.0 (3.0, 4.0), $P<0.001)$, LB (1.0 (0.0, 2.0) vs. $2.0(2.0,2.0), P<0.001), B(1.0(1.0,2.0)$ vs. $3.0(3.0,3.5), P<0.001)$ and T $(3.0(2.0,8.0)$ vs. $10.0(10.0,11.5), P<0.001)$, than the control group. Cranial MRI in NEC group revealed a widened interparenchymal space with decreased myelination. The abnormality rate of cranial MRI in the NEC group was higher than that in the control group $(P=0.001)$. The GDS assessment indicated that NEC children had inferior performance and lower mean scores than the control group in the subdomains of gross motor (71 (SD =6.41) vs. $92(S D=11.37), P<0.001)$, fine motor (67 (SD =9.34) vs. $96(S D=13.69)$, adaptive behavior $(76(S D=9.85)$ vs. $95(S D=14.38), P=0.001)$, language (68 (SD =12.65) vs. $95(S D=11.41), P<0.001)$, personal-social responses $(80(S D=15.15)$ vs. $93(S D=14.75), P=0.037)$ and in overall DQ $(72(S D=8.66)$ vs. $95(S D=11.07), P<0.001)$. The logistic binary regression analysis revealed that the NEC patients had a significantly greater risk of neurodevelopmental delay than the control group (aOR $=27.00,95 \%$ $\mathrm{Cl}=2.561-284.696, P=0.006)$. Confirmed by Spearman's rank correlation analysis, neurodevelopmental outcomes were significantly predicted by the 1 st aEEG Burdjalov score $(r=0.603, P=0.001)$. An abnormal 1 st Burdjalov score has predictive value for neurodevelopmental delay with high specificity (84.62\%) and positive predictive value (80.00\%).

Conclusions: Children with NEC are more likely to develop neurodevelopmental delay. There is high specificity and PPV of early aEEG in predicting neurodevelopmental delay.

\footnotetext{
*Correspondence: linzhenlang@hotmail.com; 254340319@qq.com

${ }^{1}$ Department of Neonatology, the Second Affiliated Hospital and Yuying

Children's Hospital of Wenzhou Medical University, 109 West Xueyuan

Road, Wenzhou 325027, Zhejiang, China

Full list of author information is available at the end of the article
}

(C) The Author(s) 2021. Open Access This article is licensed under a Creative Commons Attribution 4.0 International License, which permits use, sharing, adaptation, distribution and reproduction in any medium or format, as long as you give appropriate credit to the original author(s) and the source, provide a link to the Creative Commons licence, and indicate if changes were made. The images or other third party material in this article are included in the article's Creative Commons licence, unless indicated otherwise in a credit line to the material. If material is not included in the article's Creative Commons licence and your intended use is not permitted by statutory regulation or exceeds the permitted use, you will need to obtain permission directly from the copyright holder. To view a copy of this licence, visit http://creativecommons.org/licenses/by/4.0/. The Creative Commons Public Domain Dedication waiver (http://creativeco mmons.org/publicdomain/zero/1.0/) applies to the data made available in this article, unless otherwise stated in a credit line to the data. 
Keywords: Preterm infants, Cerebral function monitoring, Necrotizing enterocolitis

\section{Introduction}

Premature infants with neonatal necrotizing enterocolitis (NEC) are at high risk for death or adverse neurodevelopmental outcomes. Understanding the morbidity of NEC with a long-term follow-up would aid neonatologists and pediatric surgeons in making informed decisions in providing care for these patients. However, neurodevelopmental outcomes of premature infants after NEC recovery have not been widely reported, especially in developing countries. Earlier clinical studies were summarized in a systematic review by Ree CM et al. in 2007 [1], which showed that 45\% of ELBW infants who had NEC were neurodevelopmentally impaired. Infants with NEC were significantly more likely than infants of similar age and gestation who did not develop NEC to be neurodevelopmentally impaired, including a higher risk of cerebral palsy and visual, cognitive, and psychomotor impairments. Since then, similar findings have been reported in other observational clinical studies $[2,3]$. The causes of adverse neurodevelopmental outcomes in premature infants with NEC remain to be determined. It can be multifactorial and linked to perinatal events, severity of disease, surgical treatment and complications and hospitalization.

Amplitude-integrated electroencephalogram (aEEG) is the third generation brain function monitoring technology designed by Maynard in the late 1960s [4] and has been applied in neonatal intensive care units since the 1980s [5]. aEEG involves an amplitude integration of the original EEG, and the output is $6 \mathrm{~cm} / \mathrm{h}$, which reflects the background activity. aEEG can also be used in children on ventilation or therapeutic hypothermia. At present, the application of aEEG in the neonatal intensive care unit includes hypoxic ischemic encephalopathy (HIE) and therapeutic hypothermia [6,7], neonatal convulsion [8], intracranial hemorrhage [9], severe congenital heart disease [10], metabolic diseases [11] and bilirubin encephalopathy [12]. However, the application of aEEG in brain function monitoring of premature infants is still in its infancy. Studies have shown that preterm aEEG background was associated with gestational age and corrected gestational age, and the postnatal brain function of preterm infants showed catch-up development [13, 14]. An early aEEG examination can predict the prognosis of premature neural development $[15,16]$. Abnormal aEEG tracings, such as discontinuous low voltage, low voltage, outbreak- inhibition (BS) activities, and lack of sleep-wake cycles, were confirmed to be associated with brain damage based on ultrasound and head magnetic resonance imaging (MRI) in subsequent follow-up. However, most newborns with normal aEEG backgrounds do not have such abnormalities. The purpose of this study was to analyze the relationship of aEEG tracing and neurological prognosis of preterm infants with neonatal NEC.

\section{Methods}

This study was a prospective cohort study. The inclusion criteria were preterm infants of gestational age $<32$ weeks who were hospitalized in the level III NICU of the Second Affiliated Hospital of Wenzhou Medical University between October 2017 and October 2018. The control group was set up at a ratio of 1:1 to 2 , and the children in the control group were premature infants of the same gestational age admitted at the same time. The exclusion criteria were intrauterine distress, neonatal asphyxia, intracranial hemorrhage (grade III and above), hydrocephalus, periventricular leukomalacia (PVL), HIE, bilirubin encephalopathy, intracranial infection, hypoglycemic encephalopathy, brain malformations, severe bronchopulmonary dysplasia (sBPD), intrauterine growth retardation, complex congenital heart disease, chromosomal abnormalities, and inherited metabolic diseases. All the selected children had their informed consent form signed by their families, and the study passed the hospital ethical review and approval (number LCKY2019-287).

Based on the neonatal postoperative pain assessment scale, the children's crying, oxygen concentration, vital signs, facial expression, and sleep were assessed, and those who had moderate to severe pain received analgesic treatment. Considering that the $t_{1 / 2}$ of plasma fentanyl citrate is $3 \sim 4 \mathrm{~h}$, to prevent the effect of analgesics on aEEG, infants who were not given analgesic treatment $12 \mathrm{~h}$ before and during aEEG monitoring were included in the experimental group. In infants without NEC, aEEG recordings were performed at the same gestational age and corrected gestational age.

Necrotizing enterocolitis was defined clinically, radiologically or histologically based on modified Bell's staging criteria [17]. Medical NEC was diagnosed as Bell's stage II or higher that improved after conservative treatment. Medical management included withdrawal of formula, antibiotic usage and symptomatic support measures. Patients with Bell's stage IIIB NEC or NEC without bowel perforation who continued to progress after active nonsurgical treatment were treated surgically and classified as surgNEC. In the NEC group, 6 - $\mathrm{h}$ aEEG recording was conducted during the following four time periods: $48 \mathrm{~h}$ 
(1st), 1 wk. (2nd), 2 wk. (3rd) and 3 wk. (4th) after surgery in the surgNEC group or after diagnosis in the medNEC group. In the control group, aEEG examination was completed synchronously at the same age of correction day.

The aEEG recording (NicoletoneTM Monitor) was conducted by a neonatologist. Based on the international 10-20 system of electrode placement, P3 and P4 were selected as the one-channel electroencephalograms from 2 parietal disc electrodes to obtain aEEG tracings. Only recordings with an impedance $<10 \mathrm{k} \Omega$ were analyzed. The frequencies were between $2 \sim 20 \mathrm{~Hz}$ and the signal was displayed on a semilogarithmic scale at a speed of $6 \mathrm{~cm} / \mathrm{h}$.

The aEEG tracings were reviewed by two neonatologists and an electroencephalographer who had many years of aEEG interpretation and were blinded to the clinical data. Background activity classification was carried out according to the scoring system developed by Burdjalov and colleagues [18], which consists of Co (continuity of the recording), Cy (presence of sleep-wake cycle (SWC)), LB (lower border amplitude score), and B (bandwidth), to objectively assess the developmental maturation of the premature infants to facilitate the assessment of premature infants at different gestational ages. In addition, an aEEG score was determined with regard to the following 3 characteristics: an age-appropriate background pattern according to the reference values in Olischar et al. [19]; the presence or absence of SWC [20]; and the presence or absence of electrographic seizure activity [20]. An aEEG score of ' 1 ' or 'normal aEEG' corresponded with normality in all 3 categories. A score of ' 2 ' or 'moderately abnormal aEEG' was obtained when 1 of 3 categories was classified as pathologic and ' 3 ' or 'severely abnormal aEEG' was defined as an abnormality in 2-3 of the 3 criteria [21].

Each subject underwent a complete cranial MRI 4-5 months after birth. Plain cranial MRI scans were performed by using a head coil in a 1.5 Tesla whole-body imaging system (Philips Gyroscan Intera, Best, the Netherlands.). Based on the findings of MingshuY [22], this study used a semiquantitative scoring system based on MRI morphological findings of brain injury to analyze the cranial MRI images of the included patients, with scores of 3, 2, and 1 for those with moderate/severe, mild, and no scored items, respectively. Among them, ventriculomegaly: the maximum inner diameter of choroid plexus at the level of single/bilateral ventricles $8 \sim 10 \mathrm{~mm}$ was considered mild, and $>10 \mathrm{~mm}$ was considered moderate/severe; paraventricular leukopenia was counted when there was loss of paraventricular white matter volume; parenchymal abnormalities (NPA) included extracerebral space abnormalities, such as any signal and/or morphological abnormalities in the arachnoid/subarachnoid/epidural space, which were characterized as follows: any abnormality was mild and $\geq 2$ abnormalities was considered moderate/severe. Regarding intraventricular hemorrhage, grades I and II were considered mild, and grades III and IV were considered moderate/severe. MRI findings were evaluated by one radiologist who was blinded to the clinical data.

Neurodevelopmental outcomes were assessed using the Gesell Developmental Schedules (GDS) at 12 to 18 months of age. Neurodevelopmental outcomes were classified into 2 groups according to overall developmental quotient (DQ) scores: delay, if $D Q<85$ (DQ scores $<70$ were defined as retardation; scores of $70-84$ indicated moderate delay) and normal, if $\mathrm{DQ} \geq 85$.

Statistical analyses were performed using IBM SPSS, version 25. Measurement data are expressed as the mean (SD) or median (quartiles). T-tests or Mann-Whitney U tests were used for intergroup comparisons. Categorical data were analyzed with Pearson's chi-squared test or Fisher's exact test (when the expected frequency was less than 5). Spearman's rank correlation analysis was used to analyze the correlations of aEEG to the prognosis of neurodevelopmental function. The risk factors for abnormal neurodevelopmental outcomes were analyzed with logistic binary regression. The receiver operator characteristic (ROC) curve was calculated to evaluate the predictive value of abnormal aEEG scores in predicting neurodevelopmental outcomes and enabled us to calculate the sensitivity, specificity, positive predictive value and negative predictive value. $P<0.05$ was considered statistically significant.

\section{Results}

A total of 11 preterm infants with NEC were enrolled in NEC group, among which 1 patient in surgNEC died unexpectedly due to pneumonia at 8 months of age when he had been able to turn over. A total of 17 normal preterm patients completed the follow-up study. In the NEC group, there were 10 surgNEC patients. All surgical procedures were uneventful, and vital signs were maintained at normal levels during the perioperative period. All surgNEC patients were exposed to fasting, gastrointestinal decompression (mean: 11.4 days), mechanical ventilation ( 1 for 16 days and the others for an average of 4.0 days), anti-infective treatment (broadspectrum antibiotics were used), and correction of anemia (suspended red blood cells were transfused in 8 cases). All cases were transfused with plasma, albumin and intravenous nutritional support and given dopamine therapy. There was 1 medNEC patient, and the medical management included withdrawal of formula for 7 days, intravenous nutritional support, antibiotic 
usage and symptomatic support. In the control group, the infants were fed normally, and were given intravenous nutrition and symptomatic therapy. The conditions of the two groups in terms of sex, gestational age, birth weight, Apgar score, IVH, highest serum $\mathrm{C}$-reactive protein (CRP), ibuprofen treatment rates in patent ductus arteriosus (PDA), incidence of retinopathy (ROP), BPD, mechanical ventilation (>96h), vasoactive drug use, and fasting days are shown in Table 1. As seen in the table, the proportion of males, highest CRP values, mechanical ventilation $(>96 \mathrm{~h})$, vasoactive drug use, and fasting days in NEC group were significantly higher than those in the control group. The highest CRP of the 6 infants in NEC group was greater than $200 \mathrm{mg} / \mathrm{L}$, which was included as $200 \mathrm{mg} / \mathrm{L}$ for the statistical analysis. CRP values less than $1 \mathrm{mg} / \mathrm{L}$ were included as $1 \mathrm{mg} / \mathrm{L}$ for the statistical analysis.
The aEEG features of NEC infants included discontinuous background, absence of SWC and abnormal waveforms such as epileptic electrical activity. Based on the scoring system developed by Burdjalov and colleagues [18], the Burdjalov total scores and separate entities, such as continuity, SWC and bandwidth, were compared with the reference indicators (see Table 2). The results showed that the following scores were lower in the NEC group than in the control group: Co $(1.0(0.0,2.0)$ vs. 2.0 (2.0, 2.0), $P=0.001)$, Cy $(1.0(0.0,2.0)$ vs. $3.0(3.0,4.0)$, $P<0.001)$, LB $(1.0(0.0,2.0)$ vs. $2.0(2.0,2.0), P<0.001)$, B $(1.0(1.0,2.0)$ vs. $3.0(3.0,3.5), P<0.001)$ and $\mathrm{T}(3.0(2.0$, $8.0)$ vs. $10.0(10.0,11.5), P<0.001)$. In the 2 nd aEEG, Cy (3.0 $(2.0,3.0)$ vs. $4.0(3.5,5.0), P=0.002)$, B $(3.0(2.0,3.0)$ vs. $3.0(3.0,4.0), P=0.009)$ and $\mathrm{T}(10.0(8.0,10.0)$ vs. 11.0 (10.5, 13.0), $P=0.002$ ) were significantly lower in the NEC group than in the control group. In the 3rd aEEG,

Table 1 Epidemiological data of the study group

\begin{tabular}{llll}
\hline Clinical characteristics & NEC & No NEC & $P$ value \\
\hline Male & $11 / 11$ & $6 / 17$ & $0.001^{\mathrm{a}}$ \\
Gestational age, wk & $29.07(\mathrm{SD}=1.26)$ & $29.39(\mathrm{SD}=1.15)$ & $0.509^{\mathrm{b}}$ \\
Birth weight, g & $1255.45(\mathrm{SD}=177.610)$ & $1323.75(\mathrm{SD}=152.973)$ & $0.274^{\mathrm{b}}$ \\
Small for gestational age & $0 / 10$ & $0 / 16$ & $/$ \\
Apgar-1 min & $8.0(7.0,9.0)$ & $9.00(7.5,9.0)$ & $0.517^{\mathrm{c}}$ \\
Apgar-5 min & $9.0(9.0,10.0)$ & $10.0(9.0,10.0)$ & $0.217^{\mathrm{c}}$ \\
IVH grade I or II & $3 / 11$ & $5 / 17$ & $0.903^{\mathrm{a}}$ \\
IVH grade III or IV & $0 / 10$ & $0 / 16$ & $/$ \\
Highest CRP(mg/l) & $141.0(115.0,200.0)$ & $5.0(1.0,11.5)$ & $<0.001^{c}$ \\
PDA treated by Ibuprofen & $1 / 11$ & $3 / 17$ & $1.000^{\mathrm{a}}$ \\
ROP & $3 / 11$ & $2 / 17$ & $0.353^{\mathrm{a}}$ \\
BPD & $3 / 11$ & $7 / 17$ & $0.689^{\mathrm{a}}$ \\
Mechanical ventilation, $>96 \mathrm{~h}$ & $8 / 11$ & $0 / 17$ & $<0.001^{\mathrm{a}}$ \\
Vasoactive drug use & $11 / 11$ & $0 / 17$ & $<0.001^{\mathrm{a}}$ \\
Fasting days, d & $12.0(9.0,14.0)$ & $0(0,0)$ & $<0.001^{\mathrm{c}}$ \\
\hline
\end{tabular}

Values are presented as mean (SD), median (quartiles) or number/total number. ${ }^{\mathrm{a}}$ Fisher's exact test, ${ }^{\mathrm{b}} \mathrm{T}$ test and ${ }^{\mathrm{C}}$ Mann-Whitney $\mathrm{U}$ test were used. $P<0.05$ was considered as statistically significant

Table 2 Comparison in aEEG scoring system in two groups

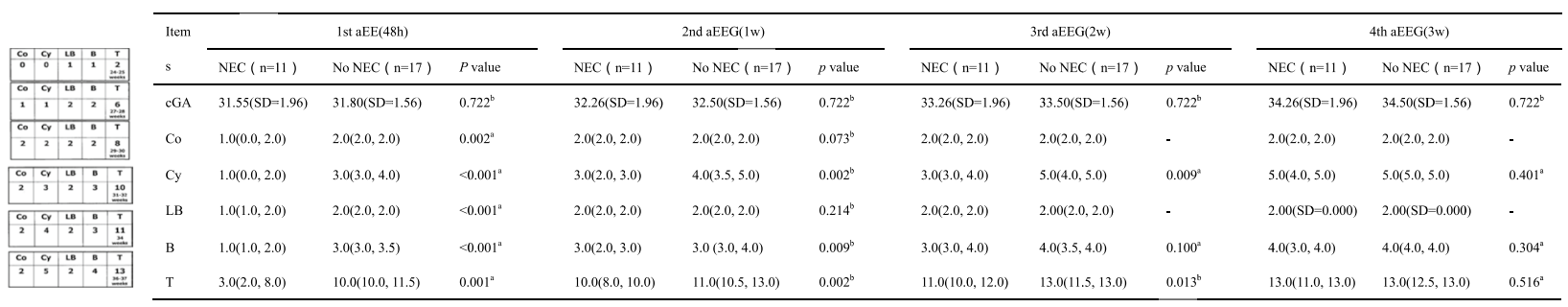

Background activity classification of aEEG was carried out according to the scoring system developed by Burdjalov and colleagues(see the left table). aEEG was conducted $48 \mathrm{~h}$ (1 st aEEG), $1 \mathrm{wk}$ (2nd aEEG), 2wk (3rd aEEG) and 3wk (4th aEEG) after surgery in surgNEC or after diagnosis in medNEC. In the control group, aEEG examination was completed synchronously at the same age of correction day. CGA, corrected gestational age. Co, continuity of the recording (0-2); Cy, presence of cycling (0-5); LB, lower border amplitude score (0-2); B, bandwidth (0-4); T, total score (0-13). ${ }^{\mathrm{a}}$ Mann-Whitney $\mathrm{U}$ test was used. ${ }^{\mathrm{b}} \mathrm{T}-$ test was used. $P<0.05$ was considered statistically significant 
Cy $(3.0(3.0,4.0)$ vs. $5.0(4.0,5.0), P=0.009)$ and $\mathrm{T}(11.0$ $(10.0,12.0)$ vs. $13.0(11.5,13.0), P=0.013)$ were significantly lower in the NEC group than in the control group. In the 4th aEEG recording, there were no significant differences between the two groups across indices.

Cranial MRI was performed in two groups in 4-5 months old. A total of 11 infants in NEC group, 17 infants in control group had undergone cranial MRI examination. There were no significant abnormalities in the control group. The rate of abnormalities on cranial MRI was higher in the NEC group than in the control group $(P=0.001)$. The magnetic resonance score was significantly higher in NEC group than in control group $(2.0(1.0,3.0)$ vs. $1.0(1.0,1.0), P=0.001)$. Abnormal cranial MRI findings in the NEC group included abnormal extracranial space $(5 / 11)$, delayed myelin development $(2 / 11)$ and intracranial hemorrhage $(1 / 11)$.

The GDS DQ assessment indicated that NEC children had inferior performance and lower mean scores than the control children in the subdomains of gross motor (71 (SD =6.41) vs. $92(\mathrm{SD}=11.37), P<0.001)$, fine motor (67 $(\mathrm{SD}=9.34)$ vs. $96(\mathrm{SD}=13.69), P<0.001)$, adaptive behavior (76 $(\mathrm{SD}=9.85)$ vs. $95(\mathrm{SD}=14.38)$, language (68 $(\mathrm{SD}=12.65)$ vs. $95(\mathrm{SD}=11.41), P<0.001)$, personalsocial responses $(80(\mathrm{SD}=15.15)$ vs. $93(\mathrm{SD}=14.748)$, $P=0.037)$ and overall DQ $(72(\mathrm{SD}=8.657)$ vs. 95 $(\mathrm{SD}=11.073), P<0.001)$. Regarding $\mathrm{DQ}$ in the NEC group, there were 2 children with scores $<70,7$ children with scores 70-84, and 1 child with a normal score $(=85)$. In the control group, there were 4 children with scores of 70-84 and 13 children with normal scores $(\geq 85)$. Logistic binary regression analysis was performed for the influencing factors of poor neurodevelopmental outcomes. The factors included in the study were financial difficulties, parental education (below middle school), maternal age $\geq 35$ years, male sex, hCRP, platelets $<100 \times 10^{\wedge} 9 / \mathrm{l}$, and NEC. After univariate analysis, statistically significant factors were included in the logistic binary regression analysis, and the results revealed that NEC patients had a significantly increased risk of abnormal neurodevelopmental outcomes compared to normal neurodevelopmental patients $(\mathrm{aOR}=27.00,95 \%$ $\mathrm{CI}=2.561-284.696, P=0.006)$ after adjusting for male sex, hCRP $>50 \mathrm{mg} / \mathrm{l}$ and platelets $<100 \times 10^{\wedge} 9 / 1$.

Based on Spearman's rank correlation analysis, there was a positive correlation between the 1st Burdjalov scores and neurodevelopmental outcomes $(r=0.476$, $P=0.012$ ) but no significant associations with the 2nd Burdjalov scores $(r=0.251, P=0.207)$ or 3rd Burdjalov score $(r=0.211, P=0.249)$. The 4th Burdjalov scores all reached the normal level relative to cGA in both groups. aEEG scores were classified as 1 (normal) and 2 (abnormal). When we worked on the assumption that infants with abnormal 1st aEEG scores to postconceptional age would be likely to suffer from neurodevelopmental delay and infants with normal aEEG scores would be neurologically normal later in life, the area under the receiver operator characteristic curve (ROC) was 0.806 $(P=0.010)$, the sensitivity was $61.74 \%$, the specificity was $84.62 \%$, the positive predictive value was $80.00 \%$, and the negative predictive value was $68.75 \%$. The correlations between aEEG scores and magnetic resonance scores were evaluated by Spearman's rank correlation analysis, and it was concluded that the first Burdjalov score was negatively correlated with magnetic resonance scores $(r=-0.397, P=0.040)$.

\section{Discussion}

In this study, we investigated the clinical characteristics, aEEG findings, MRI images, and neurological assessment of premature infants with NEC at 12 to 18 months of age. Finally, the risk of abnormal neurodevelopmental outcomes in infants with NEC and the predictive value of aEEG for neurodevelopmental delay were analyzed.

As an acute phase protein that increases during the inflammatory process, serum CRP concentrations are commonly used as a surrogate marker for infection. NEC can cause a severe overwhelming systemic inflammatory response. Several clinical studies have shown associations between infection and cerebral injury [23-28], and that the inflammatory response generated in response to NEC can result in clinical decompensation with brain injury or death [29]. In this study, Subjects were included based on strict inclusion criteria. The infants enrolled in the two groups were preterm infants of appropriate gestational age whose GA $<32$ wk. Patients were excluded for related conditions that could affect brain development. At the same time, we compared the two groups of children in terms of gestational age, birth weight, Apgar score, incidence of IVH, ROP and BPD, and there were no significant differences. In our study, the infants in NEC group showed a significant increase in CRP levels after NEC and even went through septic shock. Their mechanical ventilation time, vasoactive drug use rate and fasting days were significantly higher than those of the control group. The highest CRP level in the control group was significantly lower than that in the NEC group. Severe infection is the characteristic of infants in NEC group, then how about the brain injury?

We chose aEEG as an examination metrod for early assessment. Studies have shown that aEEG scores of premature infants with brain injury were lower than those at the corresponding gestational age or adjusted gestational age [30, 31]. Recent studies have pointed out a correlation of early aEEG parameters with short-term and long-term neurological outcomes [15, 21, 32]. Cerebral 
maturation measured by Burdjalov scores and onset of cyclicity during the early NICU course were associated with cerebral injury and other perinatal exposures [33]. Early aEEG with moderate/severe abnormalities in the background was associated with severe structural lesions detected in imaging examination in very low birth weight infants [34]. In aEEG tracings, discontinuous background or BS patterns are the results of brain damage. The presence of SWC in preterm babies matures with age, which has been shown by multiple studies [35] and is another important parameter for evaluating cerebral function. To assess the impact of NEC on preterm infants' brain development at an early stage, we conducted aEEG examination at different postoperative time periods without using sedative or pain relief drugs. Based on the study by Lisanne J. S., recovery to preoperative brain activity occurred within $24 \mathrm{~h}$ after cessation of anesthesia in most preterm infants [36]. In our study, the first examination was scheduled $48 \mathrm{~h}$ after surgery or diagnosis, and rechecked at $1 \mathrm{wk}$., $2 \mathrm{wk}$. and 3 wk. after surgery. Most infants with NEC showed abnormalities such as voltage discontinuity, absence of SWC, bandwidth enlargement or electrographic epilepticus, and the total scores of the first aEEG and the median of each item lagged behind the scores from infants at the same gestational age by more than 2 weeks, and the differences between the two groups were statistically significant. There were also significant decreases in the total scores of the second and third aEEG in the NEC group, but the median score had reached the normal value of the corresponding gestational age, indicating that the catch-up phenomenon of brain function disappeared in the NEC group, but this was not indicative of abnormalities. Therefore, this significant difference has no clinical value. In addition, we discovered that one NEC patient with intracranial hemorrhage developed seizures. Unfavorable outcomes following seizures in preterm infants include death, epilepsy and neurodevelopmental impairment [37].

Neurodevelopmental outcomes are of importance in preterm NEC infants, but after discharge, these outcomes may be influenced by many factors, such as nutrition, socioeconomic status, parents' education level and early intervention [38-40]. Indeed, some children are even unable to live with their parents. All these factors may affect children's cognitive and social abilities. While cranial MRI examination at term-equivalent age can avoid these factors and show brain development at the structural level. At the same time, we compared the two groups of children in terms of economic factors, parental education, maternal age, and family income, and there were no significant differences. Neonatal brain development is in a period of glial cell maturation and white matter fiber myelin formation, during which brain biochemical composition and water content change greatly, with complex MRI signal changes. Brain MRI in preterm infants is characterized by thin cortex, high water content in white matter (decreased myelination) and widened interparenchymal space. It has been shown that preterm infants with surgNEC showed severe WMI on brain MRI [41]. And in our study, 6/11 NEC infants, including one medNEC patient, had brain MRI images with some of the above anomalies, which might demonstrate neurodevelopmental delay.

Then how about the neurodevelopmental outcomes of these premature infants? In this study, neurodevelopmental outcomes were assessed at 12 to 18 months of age using GDS in the NEC group. It has been shown that the mental and motor development of NEC survivors has been shown to be significantly lower than that of normal premature infants [42-45]. A follow-up study at age 7 found that children with NEC had an increased incidence of cerebral palsy and hyperactivity, as well as impaired reading, writing, math and social skills [46]. Our findings are consistent with the above results. The DQ scores for gross motor, fine motor, adaptive behavior and language were significantly lower in the NEC group than in the control group, indicating the existence of neurodevelopmental delay. The NEC patients had a significantly increased risk of abnormal neurodevelopmental outcomes compared to non-NEC patients after adjusting for sex, hCRP and platelets numbers. Regarding sex, based on coincidence, all infants in the NEC group were male. Does NEC have gender susceptibility? Not currently supported [47].

Can aEEG be used to predict neurological outcome? Our study indicated that neurodevelopmental delay was associated with $48 \mathrm{~h}$ aEEG Burdjalov scores. We found a high specificity of $84.62 \%$ and a positive predictive value of $80.00 \%$ for abnormal early aEEG ( $48 \mathrm{~h}$ ) with respect to an adverse neurological prognosis. In addition, there was a negative correlation between the magnetic resonance and the 1st aEEG scores; that is, the higher the magnetic resonance score was, the lower the aEEG score was. This showed that aEEG examination in the early stage of brain injury has certain predictive value for brain imaging abnormalities as well as prognosis, which is worthy of further study.

The shortcoming of this study is that the sample size was relatively small. This is because of the gradual improvement in premature infant management in Wenzhou area and of the remarkable achievements in the prevention and treatment of complications. In addition, NEC infants were not divided into the surgery group and the medicine group, and we suggest further studies in qualified units. 


\section{Conclusions}

In summary, early aEEG $48 \mathrm{~h}$ after NEC diagnosis or surgery suggested a discontinuous background, absence of SWC and abnormal waveforms, such as epileptic electrical activity. Cranial MRI can reveal neurodevelopmental problems or severe intracranial hemorrhage. Prognosis at 12 to 18 months of age suggested that NEC children are more likely to develop neurodevelopmental delay. There was high specificity and PPV of early abnormal Burdjalov scores $(48 \mathrm{~h})$ in predicting neurodevelopmental delay.

\section{Abbreviations}

aEEG: Amplitude-integrated electroencephalography; NEC: Neonatal necrotizing enterocolitis; GDS: Gesell Developmental Schedules; DQ: Development quotient; BPD: Bronchopulmonary dysplasia; CRP: C-reactive protein; MRI: Magnetic resonance imaging.

\section{Acknowledgments}

We thank all the children and their families for participating in this study.

\section{Authors' contributions}

SC performed project design, medical records collection, and article writing. XXX and SL performed aEEG tracing interpretation and assisted in case collection. JHZ performed subject design guidance and paper modification. LDL performed Gesell scoring. MLZ, ZQY and SQC assisted in follow-up of the discharged patients. ZLL performed paper modification, and YLL performed quality control and statistical analysis. All authors have read and approved the final manuscript

\section{Authors' information}

Intentionally left blank.

\section{Funding}

This study was supported by Wenzhou Municipal Science and Technology Bureau (Application No.Y20180239).

\section{Availability of data and materials}

The datasets generated and analysed during the current study are not publicly available but are available from the corresponding author on reasonable request.

\section{Declarations}

\section{Ethics approval and consent to participate}

All methods were performed in accordance with the relevant guidelines and regulations. Written informed consents have been obtained from the parents of subjects under 16 years of age for this study, and has got ethics approval and consent by Research Ethics Committee of the Second Affiliated Hospital of Wenzhou Medical University. The Ethical Approval Number was LCKY2019-287.

\section{Competing interests}

The authors declare that they have no competing interests.

\section{Author details \\ ${ }^{1}$ Department of Neonatology, the Second Affiliated Hospital and Yuying Children's Hospital of Wenzhou Medical University, 109 West Xueyuan Road, Wenzhou 325027, Zhejiang, China. ${ }^{2}$ Children's Rehabilitation Department, the Second Affiliated Hospital and Yuying Children's Hospital of Wenzhou Medical University, Wenzhou, Zhejiang, China.}

Received: 28 June 2021 Accepted: 2 December 2021 Published online: 20 December 2021

\section{References}

1. Rees CM, Pierro A, Eaton S. Neurodevelopmental outcomes of neonates with medically and surgically treated necrotizing enterocolitis. Arch Dis Child Fetal Neonatal Ed. 2007;92:193-9.

2. Shah TA, Meinzen-Derr J, Gratton T, Steichen J, Donovan EF, Yolton K, et al. Hospital and neurodevelopmental outcomes of extremely low-birthweight infants with necrotizing enterocolitis and spontaneous intestinal perforation. J Perinatol. 2012;32:552-8.

3. Wadhawan R, Oh W, Hintz SR, Blakely ML, Das A, Bell EF, et al. Neurodevelopmental outcomes of extremely low birth weight infants with spontaneous intestinal perforation or surgical necrotizing enterocolitis. J Perinatol. 2014;34:64-70.

4. Maynard DE. EEG analysis using an analogue frequency analyser and a digital computer. Electroencephalogr Clin Neurophysiol. 1967;23:487.

5. Viniker DA, Maynard DE, Scott DF. Cerebral function monitor studies in neonates. Clin EEG Neurosci. 1984;15:185-92.

6. Gluckman PD, Wyatt JS, Azzopardi D, Ballard R, Edwards AD, Ferriero DM, et al. Selective head cooling with mild systemic hypothermia after neonatal encephalopathy: multicentre randomised trial. Lancet. 2005;365:663-70.

7. Thoresen M, Hellstrom-Westas L, Liu X, de Vries LS. Effect of hypothermia on amplitude-integrated electroencephalogram in infants with asphyxia. Pediatrics. 2010;126:e131-9. https://doi.org/10.1542/peds.2009-2938.

8. Shellhaas RA, Soaita Al, Clancy RR. Sensitivity of amplitude-integrated electroencephalography for neonatal seizure detection. Pediatrics. 2007;120:770-7. https://doi.org/10.1542/peds.2007-0514.

9. Benavente-Fernández I, Lubián-López SP, Jiménez-Gómez G, LechugaSancho AM, Garcia-Alloza M. Low-voltage pattern and absence of sleepwake cycles are associated with severe hemorrhage and death in very preterm infants. Eur J Pediatr. 2014;174:85-90.

10. Mulkey SB, Yap VL, Bai S, Ramakrishnaiah RH, Glasier CM, Bornemeier RA, et al. Amplitude-integrated EEG in newborns with critical congenital heart disease predicts preoperative brain magnetic resonance imaging findings. Pediatr Neurol. 2015;52:599-605.

11. Olischar M, Shany E, Aygn C, Azzopardi D, Hunt RW, Toet MC, et al. Amplitude-integrated electroencephalography in newborns with inborn errors of metabolism. Neonatology. 2012;102:203-11.

12. Zhang L, Zhou Y, Li X, Cheng T. Hyperbilirubinemia influences sleepwake cycles of term newborns in a non-linear manner. PLoS One. 2017;12:e0169783.

13. Niemarkt HJ, Andriessen P, Peters CHL, Pasman JW, Zimmermann LJ, Bambang OS. Quantitative analysis of maturational changes in EEG background activity in very preterm infants with a normal neurodevelopment at 1year of age. Early Hum Dev. 2010;86:219-24.

14. Ju H, Kim LH, Gue SK, Sim H, Sun E, Won C, et al. Effects of postnatal age and aminophylline on the maturation of amplitude-integrated electroencephalography activity in preterm infants. Neonatology. 2010;98:245-53.

15. Soubasi V, Mitsakis K, Sarafidis K, Griva M, Nakas CT, Drossou V. Early abnormal amplitude-integrated electroencephalography (aEEG) is associated with adverse short-term outcome in premature infants. Eur J Paediatr Neurol. 2012;16:625-30.

16. Ralser E, Neubauer V, Pupp-Peglow U, Kiechl-Kohlendorfer U, Griesmaier E. Amplitude-integrated electroencephalography can predict neurodevelopmental outcome at 12 months of corrected age in very preterm infants. Acta Paediatr Int J Paediatr. 2017;106:594-600.

17. Walsh MC, Kliegman RM, Fanaroff AA. Necrotizing enterocolitis: a practitioner's perspective. Pediatr Rev Am Acad Pediatr. 1988;9:219-26.

18. Burdjalov VF, Baumgart S, Spitzer AR. Cerebral function monitoring: a new scoring system for the evaluation of brain maturation in neonates. Pediatrics. 2003;112:855-61. https://doi.org/10.1542/peds.112.4.855.

19. Monika O, Katrin K, Stefan K, Margot H, Christina K, Ernst R, et al. Reference values for amplitude-integrated electroencephalographic activity in preterm infants younger than 30 weeks' gestational age. Pediatrics. 2004;113:e61-6.

20. Hellstro m-Westas L, Rosen I, de Vries LS, Greisen G. Amplitude-integrated EEG classification and interpretation in preterm and term infants. Neo Rev. 2006;7:e76-87. https://doi.org/10.1542/neo.7-2-e76.

21. Klebermass K, Olischar M, Waldhoer T, Fuiko R, Pollak A, Weninger M. Amplitude-integrated EEG pattern predicts further outcome in preterm infants. Pediatr Res. 2011;70:102-8. 
22. Mingshu Y, Li WQZPZCQ. Predicting the outcomes at discharge of neonatalbacterial meningitis:a semi-quantitative MRI_based-score system analysis. Chin J Evd Based Pediatr. 2015;10:101-7.

23. Dammann O, Leviton A, Gappa M, Dammann CEL. Lung and brain damage in preterm newborns, and their association with gestational age, prematurity subgroup, infection/inflammation and long term outcome. BJOG Int J Obstet Gynaecol. 2005:112:4-9.

24. Sharabi H, Khatib N, Ginsberg Y, Weiner Z, Ross MG, Tamar BK, et al. Therapeutic $\mathrm{N}$-acetyl-cysteine ( $\mathrm{Nac}$ ) following initiation of maternal inflammation attenuates long-term offspring cerebral injury, as evident in magnetic resonance imaging (MRI). Neuroscience. 2019;403:118-24.

25. Galinsky R, Lear CA, Dean JM, Wassink G, Dhillon SK, Fraser M, et al. Complex interactions between hypoxia-ischemia and inflammation in preterm brain injury. Dev Med Child Neurol. 2018;60:126-33.

26. Van Steenwinckel J, Schang AL, Sigaut S, Chhor V, Degos V, Hagberg H, et al. Brain damage of the preterm infant: new insights into the role of inflammation. Biochem Soc Trans. 2014;42:557-63.

27. Kapitanović Vidak H, Catela Ivković T, Jokić M, Spaventi R, Kapitanović S. The association between proinflammatory cytokine polymorphisms and cerebral palsy in very preterm infants. Cytokine. 2012:58:57-64.

28. Alshaikh B, Yusuf K, Sauve R. Neurodevelopmental outcomes of very low birth weight infants with neonatal sepsis: systematic review and metaanalysis. J Perinatol. 2013;33:558-64.

29. Adams-Chapman I, Stoll BJ. Neonatal infection and long-term neurodevelopmental outcome in the preterm infant. Curr Opin Infect Dis. 2006;19:290-7.

30. Fogtmann EP, Plomgaard AM, Greisen G, Gluud C. Prognostic accuracy of electroencephalograms in preterm infants: a systematic review. Pediatrics. 2017;139:e20161951. https://doi.org/10.1542/peds.2016-1951.

31. Ters NME, Vesoulis ZA, Liao SM, Smyser CD, Mathur AM. Impact of brain injury on functional measures of amplitude-integrated EEG at term equivalent age in premature infants. Nat Publ Group. 2017;37:947-52. https://doi.org/10.1038/jp.2017.62.

32. Jiang C, Yang Y, Chen L. Early amplitude-integrated EEG monitoring $6 \mathrm{~h}$ after birth predicts long-term neurodevelopment of asphyxiated late preterm infants. Eur J Pediatr. 2015;174:1043-52.

33. Reynolds LC, Pineda RG, Mathur A, Vavasseur C, Shah DK, Liao S, et al. Cerebral maturation on amplitude-integrated electroencephalography and perinatal exposures in preterm infants. Acta Paediatr Int J Paediatr. 2014;103:e96-100

34. Magalhães LVS, Winckler MIB, Bragatti JA, Procianoy RS, Silveira RC. Early amplitude-integrated electroencephalogram as a predictor of brain injury in newborns with very low birth weight: a cohort study. J Child Neurol. 2018:33:659-63.

35. Sisman J, Campbell DE, Brion LP. Amplitude-integrated EEG in preterm infants: maturation of background pattern and amplitude voltage with postmenstrual age and gestational age. J Perinatol. 2005;25:391-6.

36. Stolwijk $L$, Weeke LC, De VLS, Van MYA. Effect of general anesthesia on neonatal aEEG - a cohort study of patients with non-cardiac congenital anomalies. PLoS One. 2017;12:e0183581.

37. Spagnoli C, Falsaperla R, Deolmi M, Corsello G, Pisani F. Symptomatic seizures in preterm newborns: a review on clinical features and prognosis. Ital J Pediatr. 2018:44:1-7.

38. Blakstad MM, Smith ER, Etheredge A, Locks LM, McDonald CM, Kupka $\mathrm{R}$, et al. Nutritional, socioeconomic, and delivery characteristics are associated with neurodevelopment in Tanzanian children. J Pediatr. 2019:207:71-9.

39. Burnett AC, Cheong JLY, Doyle LW. Biological and social influences on the neurodevelopmental outcomes of preterm infants. Clin Perinatol. 2018:45:485-500.

40. McGowan EC, Vohr BR. Neurodevelopmental follow-up of preterm infants: what is new? Pediatr Clin N Am. 2019:66:509-23.

41. Shin SH, Kim EK, Yoo H, Choi YH, Kim S, Lee BK, et al. Surgical necrotizing Enterocolitis versus spontaneous intestinal perforation in white matter injury on brain magnetic resonance imaging. Neonatology. 2016:110:148-54

42. Dilli D, Eras Z, Ulu HÖ, Dilmen U, Şakrucu ED. Does necrotizing enterocolitis affect growth and neurodevelopmental outcome in very low birth weight infants? Pediatr Surg Int. 2012;18:471-6.
43. Martin CR, Dammann O, Allred EN, Patel S, O'Shea TM, Kuban KCK, et al. Neurodevelopment of extremely preterm infants who had necrotizing enterocolitis with or without late bacteremia. J Pediatr. 2010;157:751-6.

44. Hintz SR, Kendrick DE, Stoll BJ, Vohr BR, Fanaroff AA, Donovan EF, et al. Neurodevelopmental and growth outcomes of extremely low birth weight infants after necrotizing enterocolitis. Pediatrics. 2005:115:696-703.

45. Robinson JR, Kennedy C, van Arendonk KJ, Green A, Martin CR, Blakely ML. Neurodevelopmental considerations in surgical necrotizing enterocolitis. Semin Pediatr Surg. 2018;27:52-6.

46. Pike K, Brocklehurst P, Jones D, Kenyon S, Salt A, Taylor D, et al. Outcomes at 7 years for babies who developed neonatal necrotising enterocolitis: the ORACLE children study. Arch Dis Child Fetal Neonatal Ed. 2012:97:F318-22.

47. Brigit MCDH. Risk factors for necrotizing enterocolitis in premature infants: how race, gender, and health status contribute. Adv Neonatal Care. 2008;8:285-90.

\section{Publisher's Note}

Springer Nature remains neutral with regard to jurisdictional claims in published maps and institutional affiliations.
Ready to submit your research? Choose BMC and benefit from:

- fast, convenient online submission

- thorough peer review by experienced researchers in your field

- rapid publication on acceptance

- support for research data, including large and complex data types

- gold Open Access which fosters wider collaboration and increased citations

- maximum visibility for your research: over $100 \mathrm{M}$ website views per year

At BMC, research is always in progress.

Learn more biomedcentral.com/submissions 